\title{
Lidar sounding of volcanic plumes
}

\author{
Luca Fiorani*a ${ }^{*}$, Alessandro Aiuppa ${ }^{\mathrm{b}}$, Federico Angelini $^{\mathrm{a}}$, Rodolfo Borelli ${ }^{\mathrm{a}}$, Mario Del Franco ${ }^{\mathrm{c}}$, \\ Daniele Murra ${ }^{\mathrm{d}}$, Marco Pistilli ${ }^{\mathrm{a}}$, Adriana Puiu ${ }^{\mathrm{a}}$, Simone Santoro ${ }^{\mathrm{b}}$ \\ ${ }^{a}$ Diagnostics and Metrology Laboratory, Italian National Agency for New Technologies, Energy and \\ Sustainable Economic Development, Via Enrico Fermi 45, 00044 Frascati, Italy; ${ }^{\mathrm{E}}$ Earth and Sea \\ Sciences Department, University of Palermo, Via Archirafi 36, 90123 Palermo, Italy; 'Mathematical \\ Modeling Laboratory, Italian National Agency for New Technologies, Energy and Sustainable \\ Economic Development, Via Enrico Fermi 45, 00044 Frascati, Italy; ${ }^{\mathrm{d}}$ Radiation Sources Laboratory, \\ Italian National Agency for New Technologies, Energy and Sustainable Economic Development, \\ Via Enrico Fermi 45, 00044 Frascati, Italy
}

\begin{abstract}
Accurate knowledge of gas composition in volcanic plumes has high scientific and societal value. On the one hand, it gives information on the geophysical processes taking place inside volcanos; on the other hand, it provides alert on possible eruptions. For this reasons, it has been suggested to monitor volcanic plumes by lidar. In particular, one of the aims of the FP7 ERC project BRIDGE is the measurement of $\mathrm{CO}_{2}$ concentration in volcanic gases by differential absorption lidar. This is a very challenging task due to the harsh environment, the narrowness and weakness of the $\mathrm{CO}_{2}$ absorption lines and the difficulty to procure a suitable laser source. This paper, after a review on remote sensing of volcanic plumes, reports on the current progress of the lidar system.
\end{abstract}

Keywords: lidar, differential absorption, aerosol load, water vapor, carbon dioxide, volcanic plumes

\section{INTRODUCTION}

The composition of volcanic gases gives information on the processes inside volcanos and on the transition from quiescence to eruption. Up to now, coupled gas-geophysical studies are sparse, due to the difference in their typical sampling frequency ( $>1 \mathrm{~Hz}$ for seismic signals and $<10^{-5} \mathrm{~Hz}$ for gas data). This explains the interest of geophysicists in new techniques of gas detection, in particular for $\mathrm{CO}_{2}$, the second most abundant gas in volcanic fluids and the most directly linked to deep "pre-eruptive" volcanic degassing processes.

Lidars ${ }^{1}$ have been used in the past to determine aerosol $\operatorname{load}^{2}, \mathrm{SO}_{2}$ concentration ${ }^{3}$ and water vapor flux in volcanic plumes. ${ }^{4}$. One of the tasks of the recently begun FP7 ERC project BRIDGE ${ }^{5}$ is the lidar measurement of $\mathrm{CO}_{2}$ concentration in volcanic plumes.

A lidar is composed of a transmitter (laser) and a receiver (telescope). Its principle of operation is illustrated in Figure 1a: the backscatterers (molecules and aerosols) at the distance R from the system send back part of the laser pulse toward A, active surface of the telescope. Consequently, the analysis of the detected signal as a function of $t$, time interval between emission and detection, allows one to study the optical properties of the atmosphere along the beam, since the simple relation between $t$ and $R$ is given by:

$$
R=\frac{c t}{2}
$$

where $\mathrm{c}$ is the speed of light.

*luca.fiorani@enea.it; phone 3906 9400-5861; fax 3906 9400-5312; www.enea.it

Lidar Technologies, Techniques, and Measurements for Atmospheric Remote Sensing IX, edited

by Upendra N. Singh, Gelsomina Pappalardo, Proc. of SPIE Vol. 8894, 889407

(C) 2013 SPIE · CCC code: $0277-786 X / 13 / \$ 18 \cdot$ doi: $10.1117 / 12.2028364$

Proc. of SPIE Vol. $8894889407-1$ 
The photons detected within $\tau_{\mathrm{D}}$, detector response time, are backscattered from the layer delimited by the distances $\mathrm{R}$ and $\mathrm{R}+\mathrm{c} \tau_{\mathrm{D}} / 2$. Their number $\mathrm{n}$ is proportional to the thickness $\mathrm{c} \tau_{\mathrm{D}} / 2$ and to the backscattering coefficient $\beta$ of the involved air volume. Furthermore, in its round trip, the original pulse consisting of $\mathrm{n}_{0}$ photons is attenuated by the atmosphere. This phenomenon is quantified by the extinction coefficient $\alpha$. Moreover, $n$ is proportional to the solid angle $A / R^{2}$ and the efficiency $\zeta$ of the detection system.

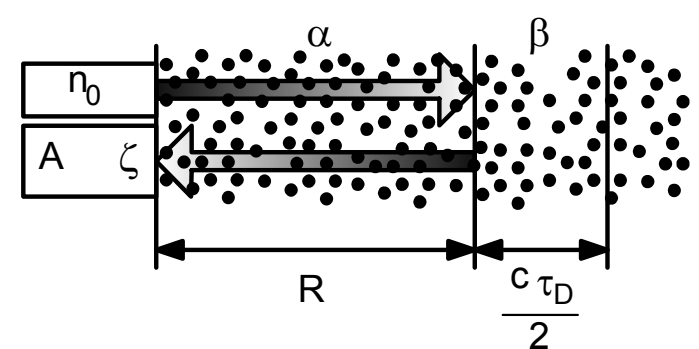

a

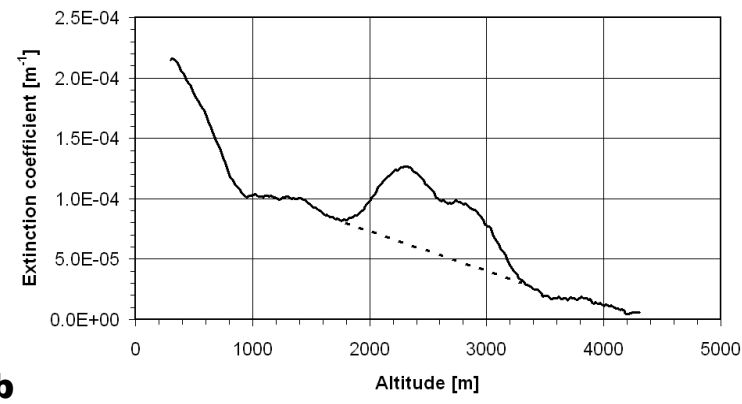

b

Figure 1. a) Lidar principle of operation. The points represent generic atmospheric scatterers (molecules and aerosols). b) Extinction coefficient retrieved from the lidar signal. The double peak from 1800 to $3300 \mathrm{~m}$ appears to superimpose over a nearly linear decay and are due to the volcanic plume (the dashed line has been added for the convenience of the reader).

On the basis of the preceding discussion, the elastic lidar equation can be written:

$$
n(R, \lambda)=n_{0}(\lambda) \zeta(\lambda) \frac{A}{R^{2}} \beta(R, \lambda) \frac{c \tau_{D}}{2} \exp \left[-2 \int_{0}^{R} \alpha\left(R^{\prime}, \lambda\right) d R^{\prime}\right] .
$$

The coefficients $\alpha$ and $\beta$ are linked one to another and are proportional to the aerosol load. An example of elastic lidar application to a volcanic plume is given in Figure $1 \mathrm{~b}$ (Mount Etna, Italy, 14 July 2008) ${ }^{2}$.

Laser remote sensing can also be used to measure the concentration of water vapor and atmospheric gases by DIAL ${ }^{1}$. This system is based on the detection of backscattered photons from laser pulses transmitted to the atmosphere at two different wavelengths. At one wavelength $\left(\lambda_{\mathrm{OFF}}\right)$, the light is almost only scattered by air molecules and aerosols, whereas at the other one $\left(\lambda_{\mathrm{ON}}\right)$, it is also absorbed by the gas under study. The difference between the two recorded signals is thus related to the pollutant concentration. More precisely, on the basis of equation (2), if $\lambda_{\mathrm{OFF}}$ and $\lambda_{\mathrm{ON}}$ are close enough, as in the case of water vapor, $\mathrm{SO}_{2}$ and $\mathrm{CO}_{2}$ measurement, the simplified DIAL equation can be derived:

$$
C(R)=\frac{1}{2\left[\sigma\left(\lambda_{\text {ON }}\right)-\sigma\left(\lambda_{\text {OFF }}\right)\right]} \frac{d}{d R} \ln \left[\frac{n\left(R, \lambda_{\text {OFF }}\right)}{n\left(R, \lambda_{\text {ON }}\right)}\right] .
$$

where $C(R)$ and $\sigma(\lambda)$ are, respectively, the concentration and the absorption cross-section of the gas molecule.

The DIAL principle of operation is illustrated in Figure 2a. An example of DIAL application to a volcanic plume is given in Figure 2b (Stromboli Volcano, Italy, 17 September 2009) ${ }^{4}$.

The lidar under development for the BRIDGE project will be positioned below the volcanic plume that will be probed with the laser beam. With such configuration, and scanning the plume in a vertical plane roughly perpendicular to the plume axis, the $\mathrm{CO}_{2}$ concentrations outside and inside the volcanic plume will be measured. In practice, the lidar will be aimed directing its optical axis by means of plain mirrors. These measurements, once integrated over the whole crosssectional area of the plume, and upon scaling to the plume transport rate (as derived from the wind speed at the plume altitude), will allow the retrieval of the $\mathrm{CO}_{2}$ flux.

As we have seen, the lidar return is linked to the optical properties of the atmosphere along the laser beam. In general, the extinction and backscattering coefficient are determined mainly by the aerosols load. This means that the lidar will not only measure gas concentrations but also aerosol loads.

The system could also be used for the measurement of wind speed ${ }^{4}$, thanks to the ability of steering the optics in different directions. According to equation (2), the number of photons backscattered by the atmosphere at a given distance from 
the instrument is proportional to the backscattering coefficient. This factor is a function of the density of aerosols responsible for the light scattering. Any change in its spatio-temporal distribution during a data acquisition will lead therefore to variations in the lidar returns from one laser shot to another. In particular, a wind flow along the beam axis will be detected from the transport of the spatial inhomogeneities of $\beta$ along the optical path.

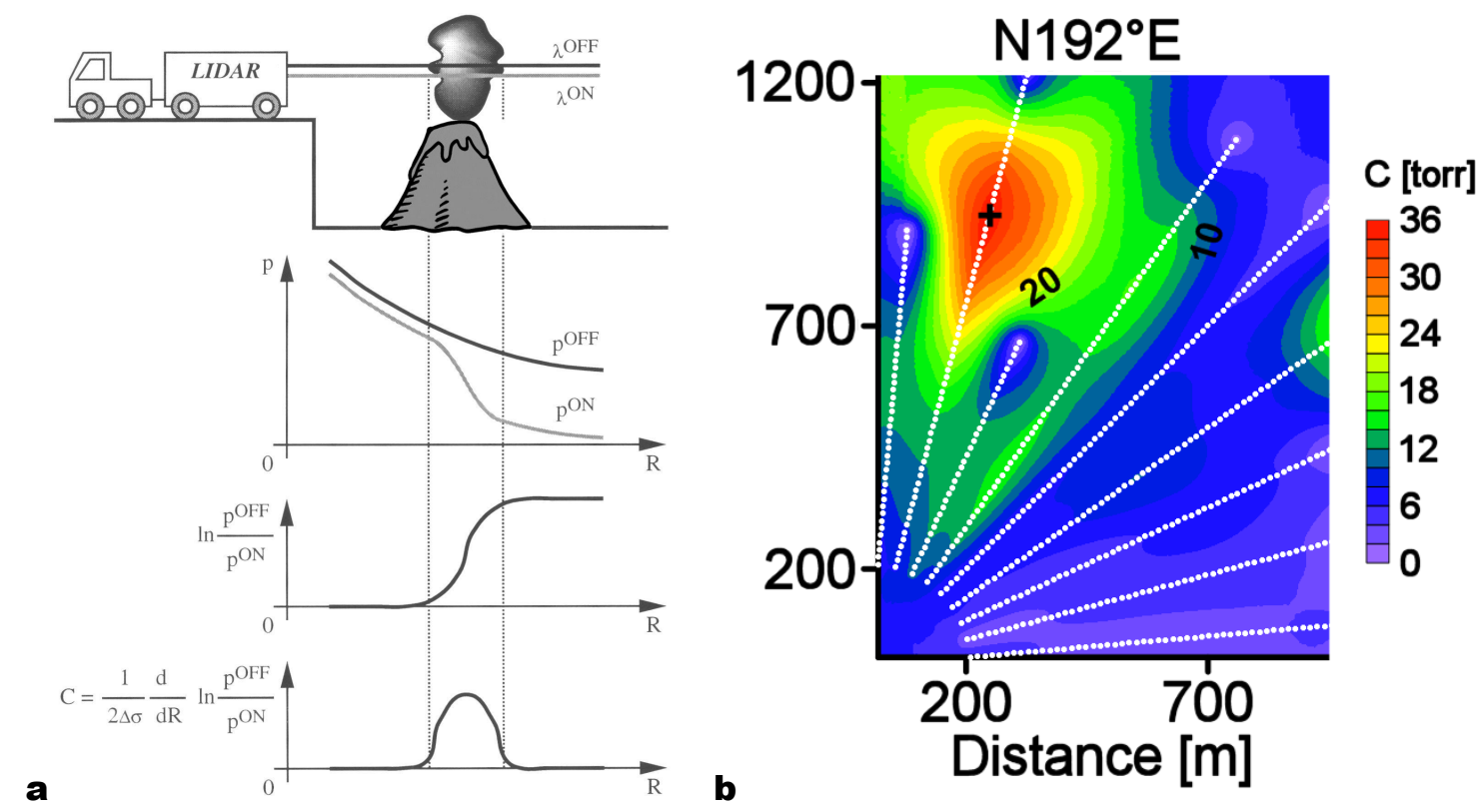

Figure 2. a) DIAL principle of operation. The figure does not represent the actual geometry of the experiment. b) Water vapor concentration retrieved by DIAL. The white points are the lidar measurements. The black cross is the point where the concentration maximum of the scan occurred.

\section{LASER CHOICE}

$\mathrm{CO}_{2}$ absorbs in the 15, 4.2, 2.1 and $1.6 \mu \mathrm{m}$ bands (in order of decreasing strength) ${ }^{6}$. Unfortunately, in the first two bands viable lasers are not available and atmospheric backscattering is rather low, so the 2.1 and $1.6 \mu \mathrm{m}$ bands have been suggested for its detection ${ }^{7}$. Nevertheless, the DIAL measurement of $\mathrm{CO}_{2}$ remains a difficult task because the absorption lines are narrow and weak ${ }^{8}$.

For all these reasons, a powerful, tunable and narrow-linewidth laser source is highly desirable. Laser technology is a rapidly evolving field. Dye lasers of new conception and OPOs (optical parametric oscillators) are now available as tunable sources in spectroscopic researches thanks to the relevant advantage of narrow linewidth. Nevertheless, up to now, all these sources have been mainly employed in the laboratory because of their relative complexity and fragility. Recently, some narrow-linewidth sources characterized by computer controlled alignment and sealed housing have been developed, making thus possible their deployment in field measurement campaigns. Fiber lasers are also a possible choice. They are more robust and small but have a very limited tunability: the lidar transmitter could contain two of them, the first one tuned at $\lambda_{\mathrm{OFF}}$ and the second one tuned at $\lambda_{\mathrm{ON}}$.

Recently, Tm,Ho:YLF lasers lasers have been employed for DIAL measurements of atmospheric $\mathrm{CO}_{2}$ for climatic studies ${ }^{9,}{ }^{10}$. Although these sources are attractive for their high energy and narrow linewidth, they have two major drawbacks: their range of tunability is very narrow (few tenths of $\mathrm{nm}$ ) if compared with that of dye lasers and OPOs (about $1 \mu \mathrm{m}$ ), thus allowing the measurement of only carbon dioxide (and not necessarily with the best line that could be out of the tunability interval) ${ }^{11}$; they are very complex system, not ready for the market and hardly suitable to field applications.

Thanks to their wide range of tunability from UV (ultraviolet) to near IR (infrared) and the occurrence of many absorption lines in these spectroscopic regions, dye lasers and OPOs will make possible to measure not only $\mathrm{CO}_{2}$, but many other species relevant to volcanic phenomena and atmospheric chemistry. 
Another advantage of dye lasers and OPOs is that they are pumped by Nd:YAG lasers. A frequency tripled Nd:YAG laser has already been employed for Raman lidar measurement of $\mathrm{CO}_{2}$ in the atmosphere ${ }^{12}$, thus giving another string to our bow, although the absolute calibration of Raman lidar remains a difficult task.

After a long and accurate research at the world's leading manufacturers, the laser system shown in Figure 3 has been purchased from Sirah. Its main characteristic is that the beam at 634 or $703 \mathrm{~nm}$ emitted by the dye laser is used to generate 1570 and $2070 \mathrm{~nm}$, respectively, by difference frequency mixing with the Nd:YAG fundamental.

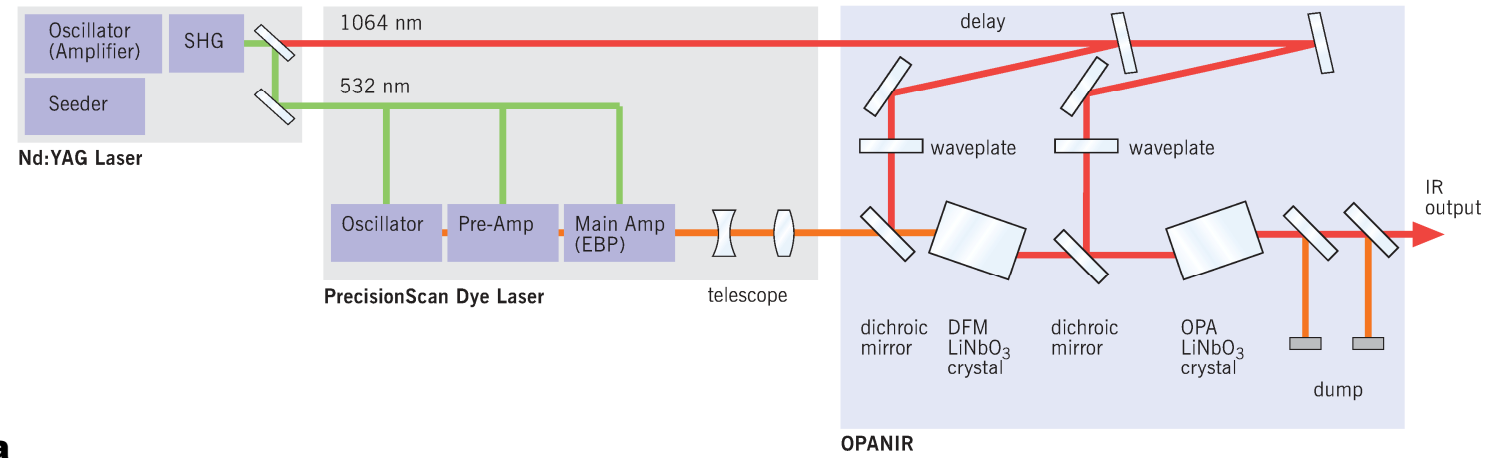

$\mathbf{a}$

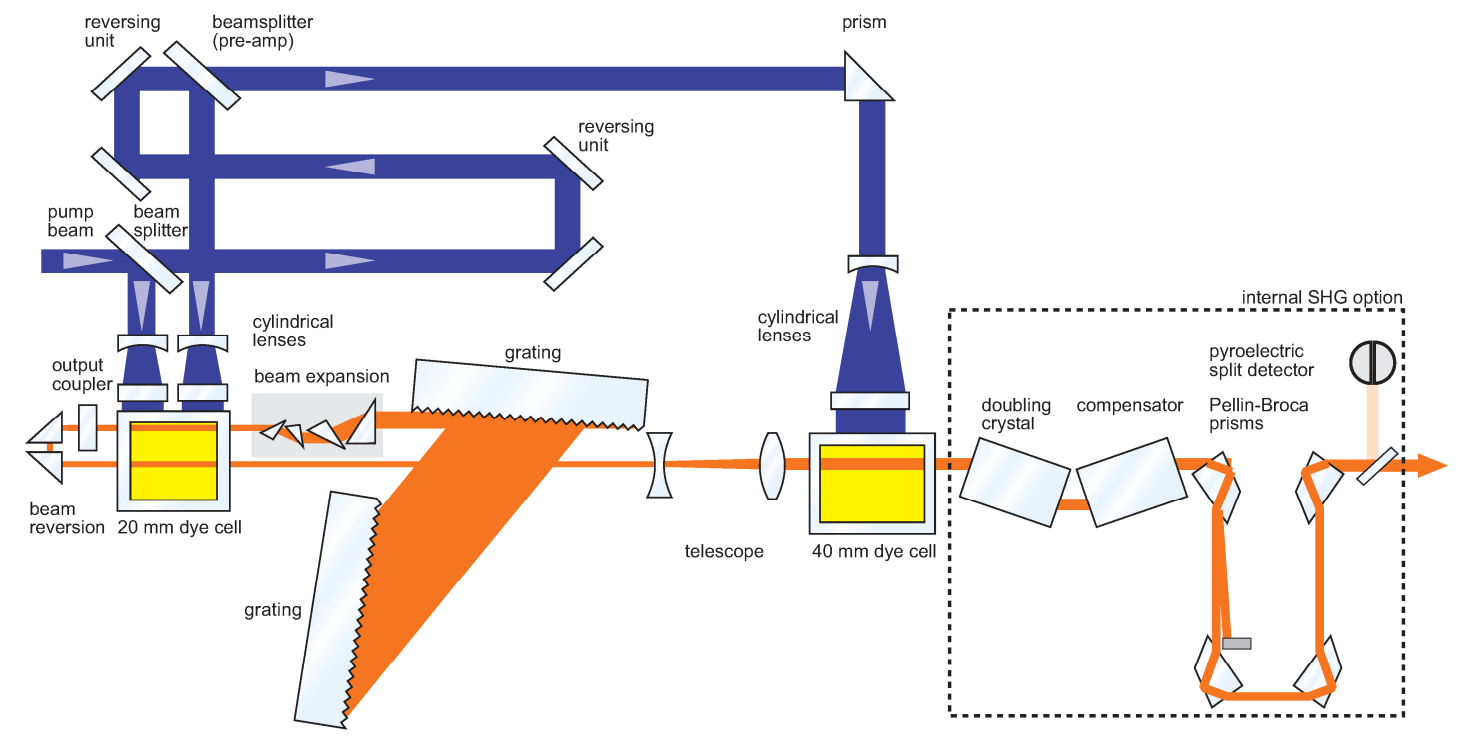

Figure 3. a) Laser system manufactured by Sirah. SHG: second harmonic generator, EBP: enhanced beam profile cell, DFM: difference frequency mixing, OPA: optical parametric oscillator. b) Detailed scheme of the dye laser and of the optional SHG.

The system has some remarkable features:

1. $10 \mathrm{pm}$ stability corresponding to 0.25 and $0.2 \mathrm{~cm}^{-1}$ stability at 1570 and $2070 \mathrm{~nm}$, respectively;

2. dynamic mode option;

3. piezo wavelength control;

4. Visible and UV emission, this latter with the second harmonic generation (optional).

The longitudinal mode spacing of the dye laser resonator is $0.018 \mathrm{~cm}^{-1}$. Its linewidth is $1.2 \mathrm{pm}$ which corresponds to 0.03 and $0.025 \mathrm{~cm}^{-1}$ at 634 and $703 \mathrm{~nm}$, respectively. This means that two longitudinal modes will be emitted. Unfortunately, the mode structure is not predictable nor constant over minutes: this means that during a lidar experiment energy could distributed in unknown and unequal parts in the two modes, causing a serious problem due to the narrow bandwidth of the $\mathrm{CO}_{2}$ absorption lines. In order to overcome this difficulty, Sirah developed the dynamic mode option (patent 
pending): a piezo changes the resonator length of the dye laser between every shot, thus modifying the longitudinal mode structure for successive laser pulses. Hence the spectral shape for successive laser pulses is statistically distributed (in our case $50 \%$ of the energy is emitted in each mode) and artifacts due to the longitudinal mode structure are suppressed.

Piezo wavelength control allows just one laser system to fire at $\lambda_{\mathrm{ON}}$ and after $1 / 10$ of second at $\lambda_{\text {OFF. }}$. This is achieved as follows:

- the rotatable Littrow grating is mounted on a tilt piezo (the silver block behind the grating with diagonal slit and black cable shown in Figure 4a; with this tilt piezo the wavelength between successive Nd:YAG laser shots is changed so that one shot is fired at $\lambda_{\mathrm{ON}}$ and the other one at $\lambda_{\mathrm{OFF}}$;

- although the piezo is fast enough for a $10 \mathrm{~Hz}$ repetition rate, the two nonlinear crystals inside the IR unit cannot be moved so fast; therefore two more nonlinear crystals have to be mounted, the first one after the standard mixing crystal and the second one after the standard amplifier crystal; these two new crystals have to be mounted with a slightly different angle in order to produce $\lambda_{\mathrm{OFF}}$ : this is achieved by a special mechanics allowing the adjustment of the new crystal to the slightly different angle with a micrometric screw (Figure $4 \mathrm{~b}$ ).

The visible and UV emissions of the system could be used for the spectroscopic measurement of other species (e.g. $\mathrm{SO}_{2}$, another key molecule of volcanic plumes).
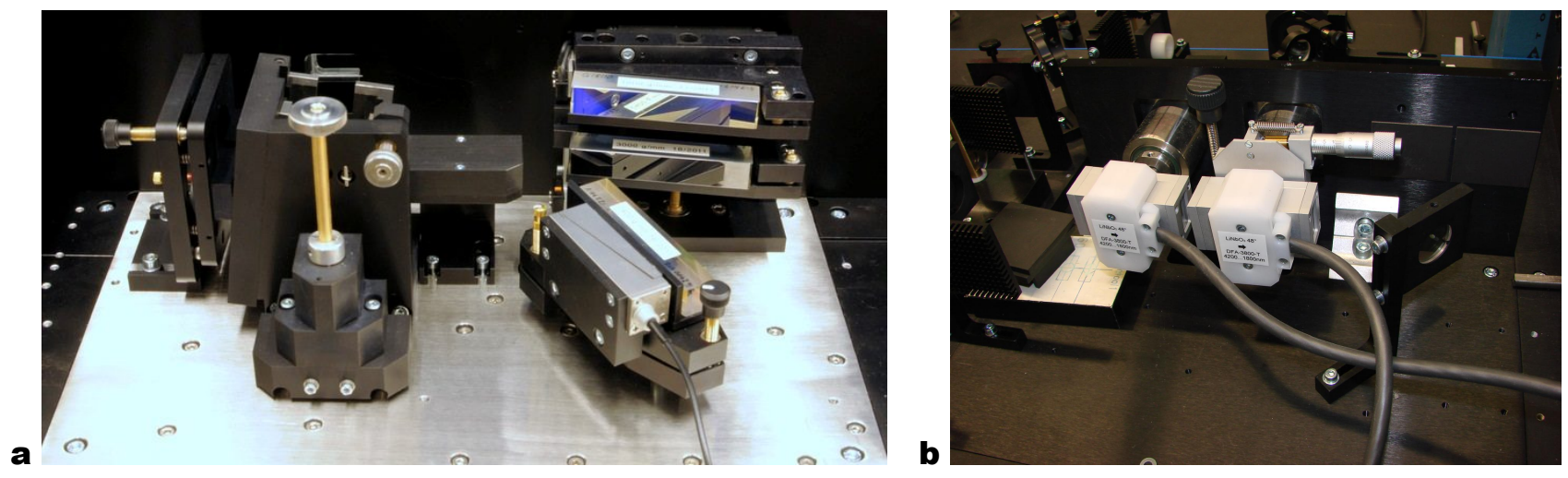

Figure 4. a) Rotatable Littrow grating. b) Assembly of the double crystal.

\section{LIDAR SIMULATION}

Two lidar system have been considered, according to Table 1 .

Table 1. Wavelengths and absorption coefficients ${ }^{8}$ of two possible lidar systems.

\begin{tabular}{ccccc}
\hline System & $\lambda_{\text {ON }}[\mathbf{n m}]$ & $\lambda_{\text {OFF }}[\mathbf{n m}]$ & $\boldsymbol{\alpha}_{\mathbf{O N}}\left[\mathbf{m}^{-1}\right]$ & $\boldsymbol{\alpha}_{\mathbf{O F F}}\left[\mathbf{m}^{-1}\right]$ \\
\hline 1 - Lidar in the $1.6 \mu$ m spectral region & 1572.6 & 1572.5 & $1.1 \times 10^{-1}$ & $9.0 \times 10^{-3}$ \\
\hline 2 - Lidar in the $2.1 \mu \mathrm{m}$ spectral region & 2011.5 & 2011.9 & 6.0 & $3.5 \times 10^{-1}$ \\
\hline
\end{tabular}

Laser beam and volcanic plume are orthogonal. This latter extends from 3000 to $3500 \mathrm{~m}$ of range. If not stated otherwise, the lidar elevation angle is $10^{\circ}$. Aerosol is simulated according to continental cumulus described by Pruppacher and Klett ${ }^{13}$ but with a 10 times less numerical concentration. Background $\mathrm{CO}_{2}$ concentration is $391 \mathrm{ppm}$, while maximum $\mathrm{CO}_{2}$ concentration in the volcanic plume ${ }^{14}$ is $2 \times 10^{5} \mathrm{ppm}$. Both aerosol and $\mathrm{CO}_{2}$ profiles are assumed to be Gaussian (Figure 5). Aerosol extinction and backscattering coefficients are retrieved at the selected wavelengths by Mie calculations. Extinction coefficients for molecules, aerosols and $\mathrm{CO}_{2}$ are shown in Figure 6.

The atmospheric transmission changes drastically between 1572 and $2011 \mathrm{~nm}$, being the absorption coefficient of $\mathrm{CO}_{2}$ two orders of magnitude larger at the longer wavelength. At $1572 \mathrm{~nm}$ the aerosol extinction is comparable to that of $\mathrm{CO}_{2}$ inside the plume, while at $2011 \mathrm{~nm}$ the $\mathrm{CO}_{2}$ extinction is dominant even in the background zone (outside the plume). 


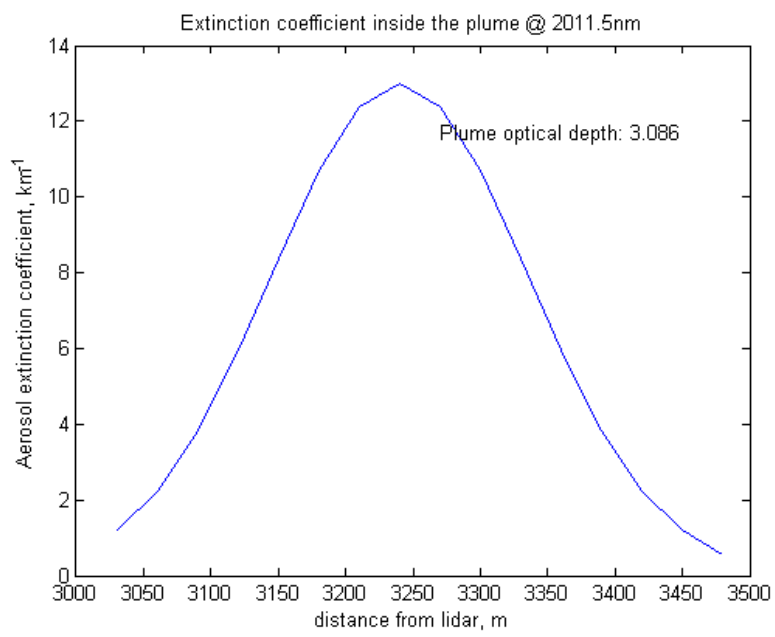

Figure 5. a) Gaussian shape of the volcanic plume.
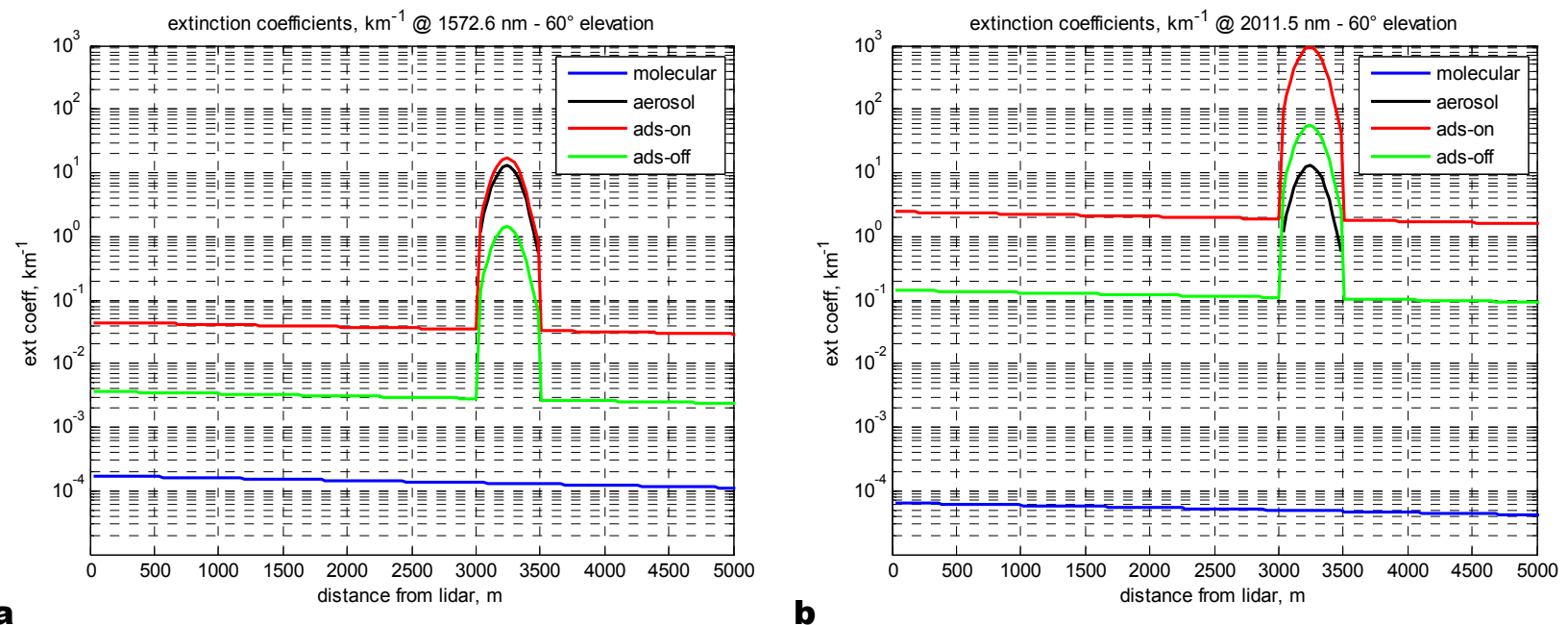

Figure 6. Extinction coefficients at a) 1572 and b) $2011 \mathrm{~nm}$ for molecules, aerosols and $\mathrm{CO}_{2}$ (lidar elevation angle $60^{\circ}$ ).
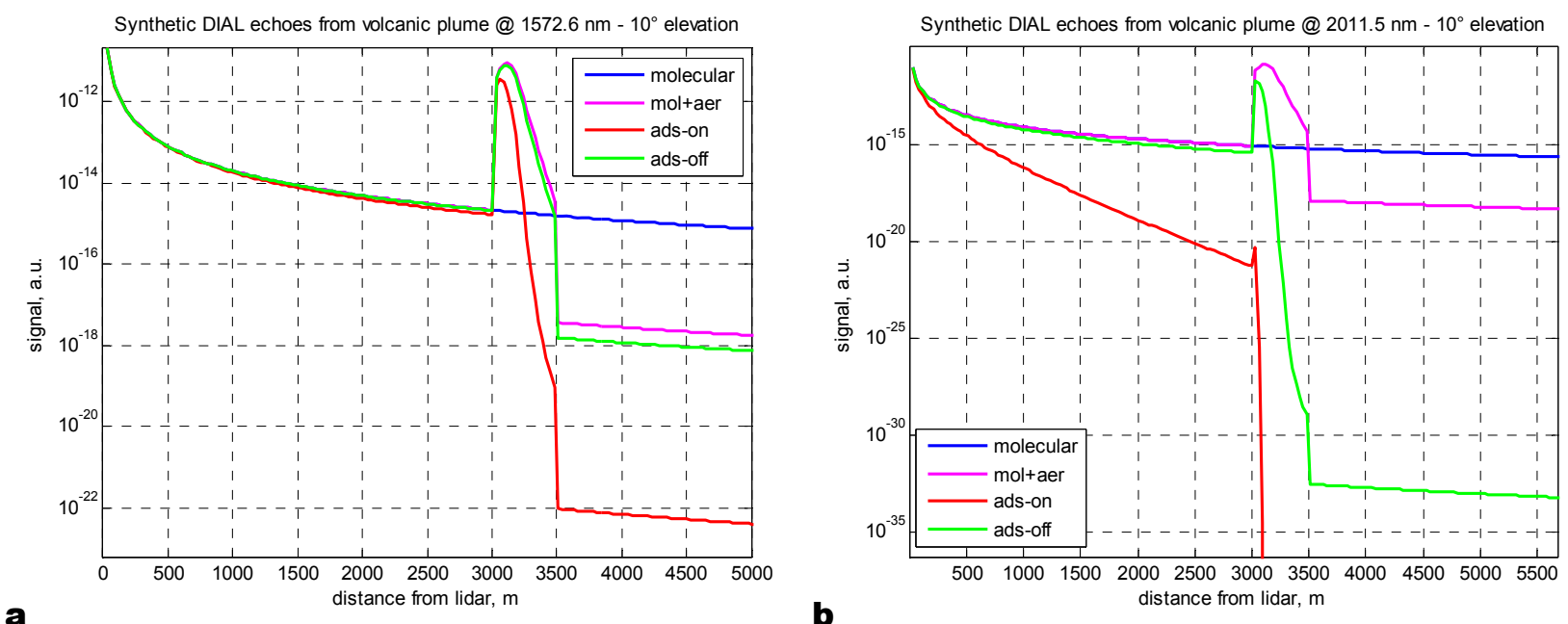

Figure 7. Lidar echoes simulated at a) 1572 and b) $2011 \mathrm{~nm}$ (lidar elevation angle $10^{\circ}$ ). 
Lidar echoes have been calculated by the lidar equation. Results are shown in Figure 7 for both 1572 and $2011 \mathrm{~nm}$. The signal at $2011 \mathrm{~nm}$ is strongly extinguished by $\mathrm{CO}_{2}$, giving an optical depth of the plume of several orders of magnitude. This would require a very sensitive instrument and background noise could be very limiting, although the background has not been taken into account to evaluate the signal-to-noise ratio. This aspect would require accurate calculations of the aerosol cross section, atmospheric radiative transfer and the knowledge of the laser power to couple the signal power to the background light.

The simulated $\mathrm{CO}_{2}$ concentration inside the volcanic plume can be regarded as the maximum possible, i.e. it is expected just outside the crater. At some km from volcanos an excess of only some tens of ppm can be found. A too strong absorption will lead to the extinction of the signal over short ranges, while a more moderate absorption will allow the observation of the plume from further distances. Crossing the plume at slant angles would provide higher sensitivity because of the increased optical path. On the other hand, it is not always possible to choose such angle over a large range, since the geometry of the observation system depends on the geometry of the plume that is determined by a lot of parameters: atmospheric stability conditions, wind-induced dispersion and capping.

For these reasons, a system operational in a wide range of conditions is desirable: according to Table 2 a system able to operate both in the 1.6 and $2.1 \mu \mathrm{m}$ spectral regions would be able to operate in many real scenarios.

Table 2. Main characteristics of two possible lidar systems.

\begin{tabular}{ccccc}
\hline System & Absorption & Sensitivity & Range & Application \\
\hline $1-$ Lidar in the $1.6 \mu \mathrm{m}$ spectral region & Moderate & Low & Long & $\begin{array}{c}\mathrm{High}_{\mathrm{CO}_{2} \text { concentrations or }} \\
\text { remote observation }\end{array}$ \\
\hline $2-$ Lidar in the $2.1 \mu \mathrm{m}$ spectral region & Strong & High & Short & $\begin{array}{c}\text { Low } \mathrm{CO}_{2} \text { concentrations or } \\
\text { close observation }\end{array}$ \\
\hline
\end{tabular}

\section{CURRENT PROGRESS}

The procurement of the main components of the lidar system (laser system, telescope, detector modules in the 1.6 and $2.1 \mu \mathrm{m}$ spectral regions, analog-to-digital converter) has been completed. The laser system is under test in our laboratory and results with a $\mathrm{CO}_{2}$-filled absorption cell confirm the specification provided by Sirah (Figure 8). The ray tracing shows that the detectors, having size of $0.5 \mathrm{~mm}(1.6 \mu \mathrm{m})$ and $1 \mathrm{~mm}(2.1 \mu \mathrm{m})$ will collect all the lidar return, taking into account the beam divergence (Figure 9). The final mechanical frame where the lidar system will be hosted has been designed (Figure 10) and is in advanced stage of realization. The LabView software controlling the experiment and the $\mathrm{C}$ program analyzing the lidar echoes are nearly completed (Figure 11). The main specifications of the lidar system are listed in Table 3.

\section{CONCLUSIONS}

The DIAL technique has been briefly reviewed, having in mind its application to the remote measurement of $\mathrm{CO}_{2}$ concentration in volcanic plumes. Unlike measurements for climatic purposes, $\mathrm{CO}_{2}$ concentration in volcanic plumes can vary of some order of magnitudes. Also the measurement geometry, and in particular the distance between system and volcano, depends heavily from the measurement scenario. For these reasons, it has been decided to develop a lidar transmitting both in the 1.6 and $2.1 \mu \mathrm{m}$ spectral regions. Lidar echoes have been simulated in an extreme case in both spectral regions. Eventually, the current progress of the system has been outlined.

\section{ACKNOWLEDGEMENTS}

The authors are grateful to R. Fantoni and A. Palucci for constant encouragement. They thank L. Cannilla for procurement assistance, Sirah and Laser Optronic for laser customization (P. Jauernik and S. De Pascalis) and installation (A. Wloka and P. Stropiccioli), Marcon Telescopes (L. Marcon) for telescope elements, LAV Coatings (E. Giannelli) for telescope coatings, Licel (B. Stein) and Hamamatsu (M. Aversa) for custom designed 1.6 and $2.1 \mu \mathrm{m}$ detectors and Impat (M. Mantovani and S. Mantovani) for mechanical development. The support from the FP7 ERC project BRIDGE, research project contract 305377 , is gratefully acknowledged. 

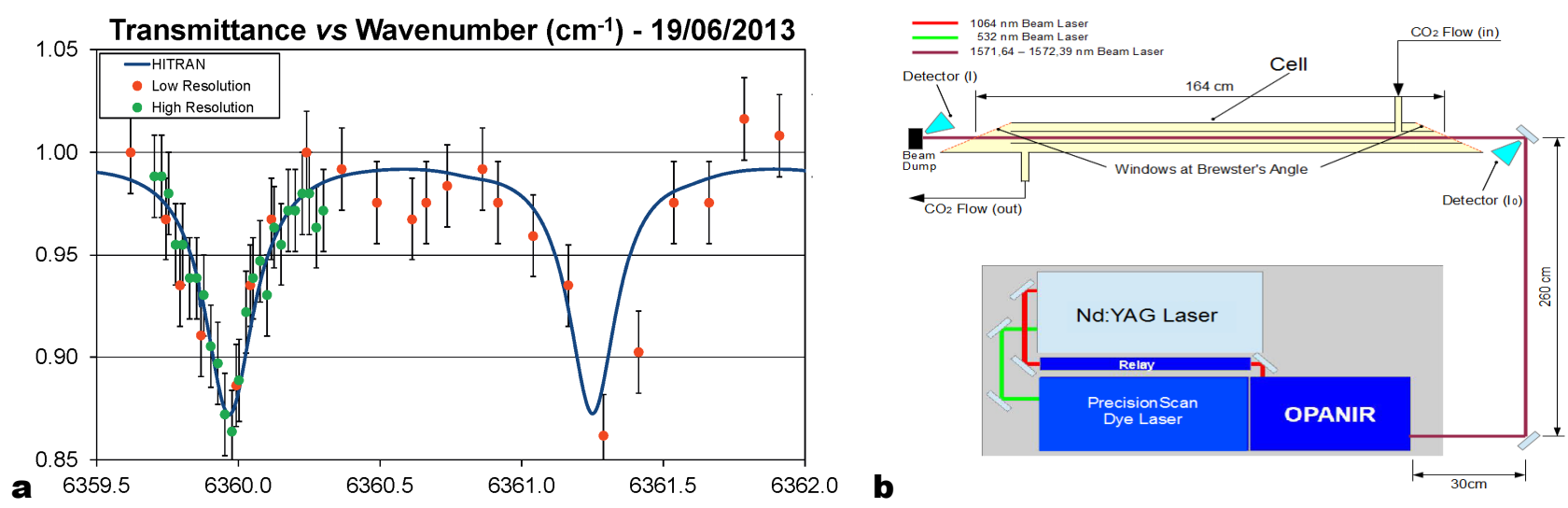

Figure 8. a) Transmittance measured in a b) $\mathrm{CO}_{2}$-filled absorption cell. Points: experimental measurement. Line: HITRAN data $^{8}$.

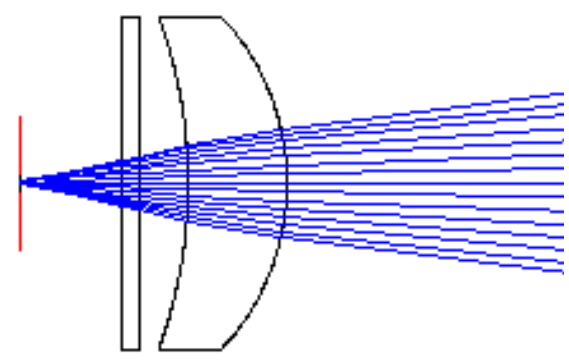

a

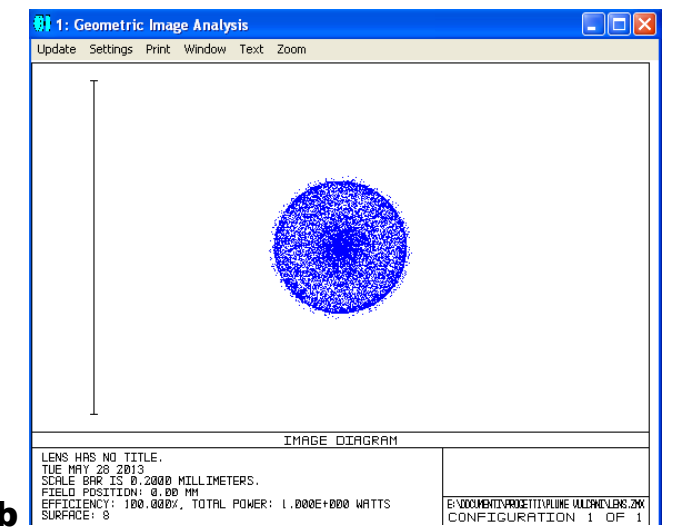

Figure 9. a) Ray-tracing of the light collected by the 1.6- $\mu \mathrm{m}$ detector (vertical line) preceded by an optical window and a meniscus lens (full angle field of view: $0.8 \mathrm{mrad}$ ). b) Spot diagram of the light collected by the $1.6-\mu \mathrm{m}$ detector.

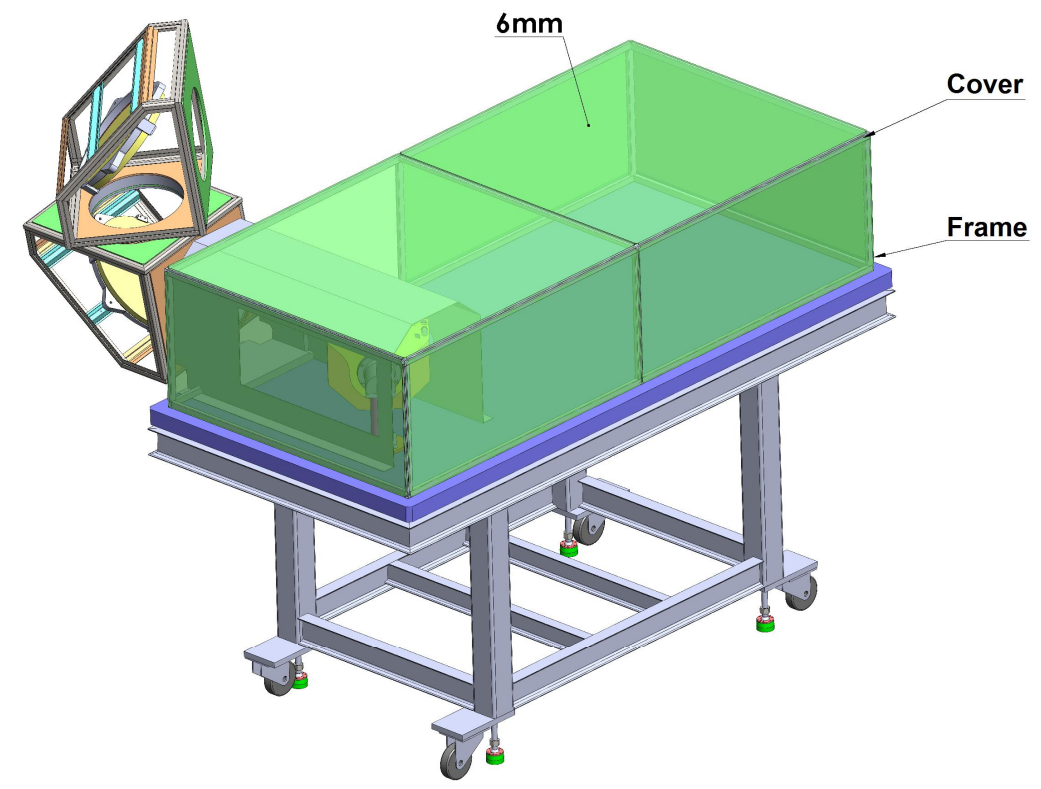

Figure 10. Mechanical frame of the lidar system (on the left two steering mirror to aim it to the target). 

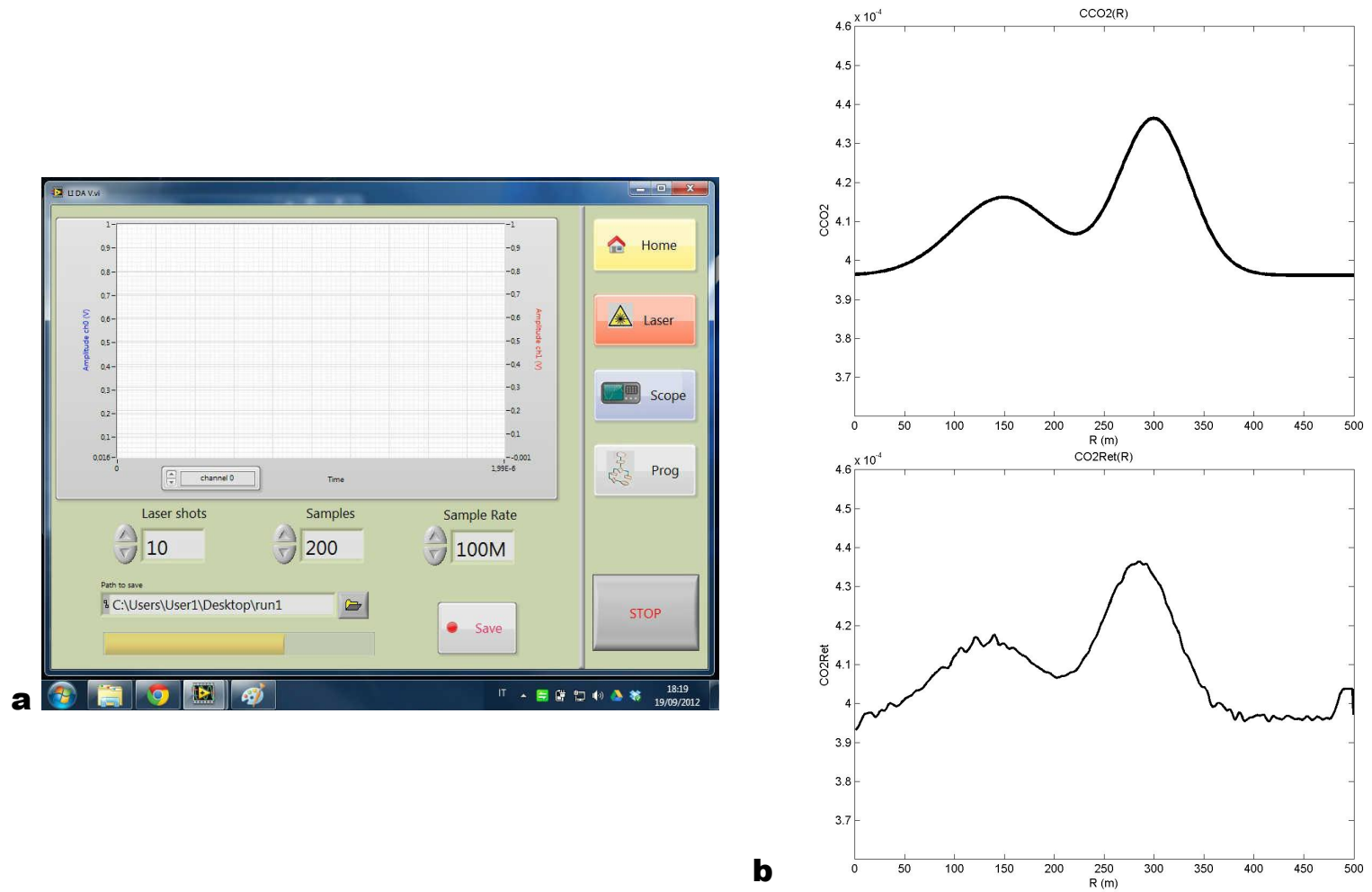

Figure 11. a) Screenshot of the LabView software controlling the experiment. b) Example of $\mathrm{CO}_{2}$ concentration simulated (top) and retrieved (bottom) by the $\mathrm{C}$ program analyzing the lidar echoes (synthetic noise has been added to the signal).

Table 3. Main specifications of the lidar system.

\begin{tabular}{|c|c|c|}
\hline \multirow{6}{*}{ Transmitter } & Pulse energy & $12 \mathrm{~mJ}$ \\
\hline & Pulse duration & $8 \mathrm{~ns}$ \\
\hline & Repetition rate & $10 \mathrm{~Hz}$ \\
\hline & Transmitted wavelengths & 1.6 and $2.1 \mu \mathrm{m}$ \\
\hline & Laser linewidth & $0.05 \mathrm{~cm}^{-1}(1.6 \mu \mathrm{m}), 0.04 \mathrm{~cm}^{-1}(2.1 \mu \mathrm{m})$ \\
\hline & Full angle beam divergence & $0.5 \mathrm{mrad}$ \\
\hline \multirow{4}{*}{ Receiver } & Mirror coating & $\mathrm{Al}$ \\
\hline & Diameter (clear aperture) & $300 \mathrm{~mm}$ \\
\hline & Focal length & $1200 \mathrm{~mm}$ \\
\hline & Full angle field of view & $0.8 \mathrm{mrad}(1.6$ and $2.1 \mu \mathrm{m})$ \\
\hline \multirow{6}{*}{ Detector modules } & Detector type & $\begin{array}{c}\text { InGaAs avalanche photodiode }(1.6 \mu \mathrm{m}) \\
\text { InGaAs PIN photodiode }(2.1 \mu \mathrm{m})\end{array}$ \\
\hline & Size & $0.5 \mathrm{~mm}$ (square, $1.6 \mu \mathrm{m}), 1 \mathrm{~mm}$ (circular, $2.1 \mu \mathrm{m})$ \\
\hline & Responsivity & $1 \mathrm{~A} \mathrm{~W}^{-1}(1.6 \mu \mathrm{m}), 1.2 \mathrm{~A} \mathrm{~W}^{-1}(2.1 \mu \mathrm{m})$ \\
\hline & Gain & $1.1 \times 10^{4} \mathrm{~V} \mathrm{~A}^{-1}(1.6 \mu \mathrm{m}), 5.1 \times 10^{4} \mathrm{~V} \mathrm{~A}^{-1}(2.1 \mu \mathrm{m})$ \\
\hline & Noise equivalent power & $4 \mathrm{pW} \mathrm{Hz}^{-1 / 2}(1.6 \mu \mathrm{m}), 10 \mathrm{pW} \mathrm{Hz}^{-1 / 2}(2.1 \mu \mathrm{m})$ \\
\hline & Bandwidth & $0 \div 10 \mathrm{MHz}(1.6$ and $2.1 \mu \mathrm{m})$ \\
\hline \multirow{2}{*}{ Analog-to-digital converter } & Dynamic range & 14 bit \\
\hline & Sampling rate & $10 \mathrm{MS} \mathrm{s}^{-1}$ \\
\hline
\end{tabular}




\section{REFERENCES}

[1] L. Fiorani, "Lidar application to litosphere, hydrosphere and atmosphere," in Progress in Laser and ElectroOptics Research, V. V. Koslovskiy, ed., 21-75 (Nova, New York, 2010).

[2] L. Fiorani, F. Colao, and A. Palucci, "Measurement of Mount Etna plume by $\mathrm{CO}_{2}$-laser-based lidar," Opt. Lett. 34, 800-802 (2009).

[3] P. Weibring, H. Edner, S. Svanberg, G. Cecchi, L. Pantani, R. Ferrara, and T. Caltabiano, "Monitoring of volcanic sulphur dioxide emissions using differential absorption lidar (DIAL), differential optical absorption spectroscopy (DOAS), and correlation spectroscopy (COSPEC)," Appl. Phys. B 67, 419-426 (1998).

[4] L. Fiorani, F. Colao, A. Palucci, D. Poreh, A. Aiuppa, and G. Giudice, "First-time lidar measurement of water vapor flux in a volcanic plume," Opt. Comm. 284, 1295-1298 (2011).

[5] European Research Council, project n. 305377: BRIDGE - Bridging the gap between gas emissions and geophysical observations at active volcanoes.

[6] P. J. Linstrom and W. G. Mallard, "The NIST Chemistry WebBook: A Chemical Data Resource on the Internet", J. Chem. Eng. Data 46, 1059-1063 (2001).

[7] R. T. Menzies and D. M. Tratt, "Differential laser absorption spectrometry for global profiling of tropospheric carbon dioxide: selection of optimum sounding frequencies for high-precision measurements," Appl. Opt. 42, 6569-6577 (2003).

[8] L. S. Rothman, I. E. Gordon, A. Barbe, D. C. Benner, P. F. Bernath, M. Birk, V. Boudon, L. R. Brown, A. Campargue, J.-P. Champion, K. Chance, L. H. Coudert, V. Dana, V. M. Devi, S. Fally, J.-M. Flaud, R. R. Gamache, A. Goldman, D. Jacquemart, I. Kleiner, N. Lacome, W. J. Lafferty, J.-Y. Mandin, S. T. Massie, S. N. Mikhailenko, C. E. Miller, N. Moazzen-Ahmadi, O. V. Naumenko, A. V. Nikitin, J. Orphal, V. I. Perevalov, A. Perrin, A. Predoi-Cross, C. P. Rinsland, M. Rotger, M. Šimečková, M. A. H. Smith, K. Sung, S. A. Tashkun, J. Tennyson, R. A. Toth, A. C. Vandaele, and J. VanderAuwera, "The HITRAN 2008 molecular spectroscopic database," J. Quant. Spectrosc. Radiat. Transfer 110, 533-572 (2009).

[9] F. Gibert, P. H. Flamant, J. Cuesta, and D. Bruneau, "Vertical 2- $\mu \mathrm{m}$ heterodyne differential absorption lidar measurements of mean $\mathrm{CO}_{2}$ mixing ratio in the troposphere," J. Atm. Ocean. Tech. 25, 1478-1497 (2008).

[10] G. J. Koch, J. Y. Beyon, F. Gibert, B. W. Barnes, S. Ismail. M. Petros, P. J. Petzar, J. Yu, E. A. Modlin, K. J. Davis, and U. N. Singh, "Side-line tunable laser transmitter for differential absorption lidar measurements of $\mathrm{CO}_{2}$ : design and application to atmospheric measurements," Appl. Opt. 47, 944-956 (2008).

[11]L. Fiorani, W. R. Saleh, M. Burton, A. Puiu, and M. Queißer, "Spectroscopic considerations on DIAL measurement of carbon dioxide in volcanic emissions," J. Optoelectron. Adv. M. 15, 317-325 (2013).

[12]D. N. Whiteman, K. Rush, I. Veselovskii, M. Cadirola, J. Comer, J. R. Potter, and R. Tola, "Demonstration measurements of water vapor, cirrus clouds, and carbon dioxide using a high-performance Raman lidar," $J$. Atm. Ocean. Tech. 24, 1377-1388 (2007).

[13]H. R. Pruppacher and J. D. Klett, Microphysics of Clouds and Precipitation (Springer, Dordrecht, 2010).

[14]T. Mori and K. Notsu, "Temporal variation in chemical composition of the volcanic plume from Aso volcano, Japan, measured by remote FT-IR spectroscopy," Geochem. J. 42, pp. 133-140 (2008). 